\title{
SER TRABALHADOR/A ENTRE POVOS INDÍGENAS: O RELATÓRIO FIGUEIREDO SOBRE TRABALHOS ESPÚRIOS EM TEMPOS DITATORIAIS'
}

Jane Felipe Beltrão²

\section{Resumo}

Discutir o que é ser trabalhador/a entre povos indígenas é o objetivo do artigo. Toma-se como ponto de partida questões sobre a organização social, considerando as dinâmicas do mundo do trabalho e as especificidades das experiências, organização, formação e construção identitária. Os argumentos são referenciados por viajantes e etnógrafos para compreender o mundo do trabalho tradicional. $\mathrm{Na}$ sequência, discute-se a imposição de regimes de trabalho espúrios ao mundo indígena, tendo por fonte o "Relatório Figueiredo" que, em tempos ditatoriais, descreve a exposição de povos indígenas a regimes de trabalho que se contrapõem à sua tradição.

Palavras-chave: Mundo do trabalho; Trabalho indígena; Povos Indígenas; Relatório Figueiredo.

\section{BE A WORKER BETWEEN INDIGENOUS PEOPLE: THE FIGUEIREDO REPORT ABOUT SPURIUS LABOR IN DICTATORIAL TIMES}

\begin{abstract}
Discussing what is it to be a worker among indigenous peoples is the goal of the article. As a starting point, questions regarding the organization of relations, considering the dynamics of the world of work and the specificities of experiences, organization, formation and construction of identity, are taken. Arguments are referred to by travelers and ethnographers to understand the world of traditional work. Next, we discuss the imposition of spurious labor regimes on the indigenous world, based on the "Figueiredo Report", which describes the exposure of indigenous peoples to work regimes that are in opposition to tradition in dictatorial times.
\end{abstract}

Keywords: World of work; Indigenous work; Indigenous peoples; Figueiredo Report.

\footnotetext{
${ }_{1}^{1}$ DOI: https://doi.org/10.22409/tn.16i31.p27372

${ }^{2}$ Antropóloga, historiadora, professora titular, docente permanente dos programas de pós-graduação em Antropologia (PPGA) e Direito (PPGD) da Universidade Federal do Pará (UFPA) e docente colaboradora do Programa de Antropologia Social (PPGAS) da Universidade de Mato Grosso do Sul (UFMS). Bolsista de produtividade em pesquisa do Conselho Nacional de Desenvolvimento Científico e Tecnológico (CNPq) nível 1C. E-mail: janebeltrao@gmail.com.
} 


\section{Povos Indígenas e o ser trabalhador/a}

O que é ser trabalhador/a entre os povos indígenas? E o que é o disciplinamento imposto pelo trabalho aos/as indígenas? O disciplinamento espúrio, vindo dos tempos coloniais, compromete os coletivos indígenas? Que fazem os povos indígenas como trabalho? Pescam, praticam a coleta, caçam, põem roça, quando estão em seus territórios? E quando estão nas cidades, após deslocamentos forçados ou não, o que fazem como trabalho? São preguntas frequentes no contexto de uma sociedade de classes, razão pela qual o texto, ora apresentado, tenta problematizar como homens e mulheres de comunidades tradicionais organizam suas relações de trabalho considerando as dinâmicas do mundo do trabalho e as especificidades de suas experiências de trabalho, organização, formação e construção identitárias.

\section{Das práticas tradicionais}

No campo da Antropologia as descrições sobre os trabalhos desenvolvidos entre coletivos indígenas foi sempre associada à organização social, pois a categoria trabalho não existe isoladamente. Entre alguns dos mais importantes viajantes e etnólogos as descrições referentes ao assunto constam, nas monografias clássicas, nos itens que se denominam: aquisição de sustento, alimentação, atividades econômicas, divisão do trabalho, divisão sexual do trabalho, trabalho e cultura material. Dificilmente, os/as profissionais da Antropologia usam a categoria trabalho, como entendida na sociedade ocidental, para descrever as práticas indígenas de sustento. ${ }^{2}$

Curt Nimuendaju inicia a descrição da divisão do trabalho entre os Apinayé, informando que "[a] derrubada e a queimada da roça cabe exclusivamente ao homem. O plantio é feito por ambos os sexos, a capinação e a colheita, igualmente." (1956: p. 69) Mais adiante, diz o autor:

"antigamente, quando terminavam de plantar as roças, saiam os Apinayé para os taboleiros, onde levavam uma vida nômade de

\footnotetext{
${ }^{2}$ Sobre o assunto conferir, entre os viajantes: Kock-Grünberg, Theodor. 2015 [1909]. Dois anos entre os Indígenas - viagens no noroeste do Brasil (1903/1905). Manaus: EDUA. Entre os etnólogos: Baldus, Herbet. 1970. Tapirapé - Tribo Tupí no Brasil Central. São Paulo: Cia Editora Nacional/EdUSP; e NImuendajú, Curt. 1956. "Os Apinayé" In Boletim do Museu Paraense Emilio Goeldi. Belém: MPEG.
} 
caçadores e coletores, até a época da colheita. Só ocasionalmente, uma ou outra família aparecia na aldeia. Hoje, como os territórios de caça ocupados na quase sua totalidade por neobrasileiros, e tendo a caça perdido a importância em favor da vida sedentária, eles saem, quando muito, durante as últimas semanas que precedem a colheita."(Nimuendju, 1956: p. 71, sic)

Entretanto, segundo os relatos de Nimuendaju, as roças não ficavam "abandonadas", pois:

"os dois txwul-putáli-txwúdn, ficavam como guardas das roças. Constroem um racho e velam com olhos de Argus $^{3}$ seus 'filhos'(idkra), como tratam os frutos, observando o crescimento de cada jurumum, cujo comprimento marcavam de tempo em tempo, com um risco no chão. Desde manhã cedo eles se ocupavam em favorecer o crescimento dos seus 'filhos' por meio de cantigas e ações mágicas, motivo porque não podem, por exemplo, dormir em posição dobrada, devendo fazê-lo em posição bem estendida." (1956: p. 71, sic)

$\mathrm{Na}$ verdade, qualquer que seja o título dado à sessão do estudo, a descrição das atividades requer compreensão ampliada, por conta da dinâmica da vida cotidiana dos povos indígenas, uma vez que cada grupo social compreende membros pertencentes a classes de idade diferenciadas, que possuem obrigações e reciprocidades associadas ao sustento dos/as membros do coletivo.

Cada atividade requer a compreensão do contexto e das pessoas envolvidas. Por exemplo, ao descrever as atividades agrícolas - como visto acima - o/a antropólogo/a considera os rituais de semeadura e colheita, pois eles estão diretamente relacionados à preparação e aos resultados do trabalho na roça. Tratando-se de caça e pesca, em geral os/as profissionais descrevem minuciosamente os instrumentos e as técnicas utilizadas pelos indígenas, descrições que vem acompanhadas de ilustrações que, no início do século $X X$, consistiam em elaborados desenhos explicando cada detalhe, hoje, com o uso corrente da fotografia, temos ensaios fotográficos e registros em vídeo para informar sobre o conhecimento dos povos indígenas. ${ }^{4}$

\footnotetext{
${ }^{3}$ Gigante da mitologia grega com cem olhos. Ao dormir, Argus fechava, apenas, a metade dos olhos, o que permitia manter-se em eterna vigília.

${ }^{4}$ Sobre registros fotográficos a respeito de trabalho entre povos tradicionais consultar: SAUTCHUK, Carlos Emanuel. "Pesca e aprendizagem: Gestação e metamorphoses no estuário do Amazonas" In: Amazônica - Revista de Antropologia. (Online) vol. 5, n. 2: p. 502-519, 2013 e SILVA, Elissandra Barros da. "Sobre aquela ponte existe um mundo: Ivaynti e os Arukwayene no Urucauá" In: Amazônica - Revista de Antropologia. (Online) vol. 8, no. 2: p. 568-608, 2016. Sautchuk observa que:
} 


\title{
É Koch-Grünberg quem descreve em detalhes a pesca no Alto Rio Negro e
} seus afluentes.

\begin{abstract}
"na época das águas baixas, nos meses de dezembro até março, quando secam os pequenos afluentes, os peixes retiram-se para o rio principal e permanecem nos lugares mais profundos abaixo das corredeiras e cachoeiras e nos numerosos lagos que estão ligados aos rios. A localização das aldeias indígenas torna-se menos favorável na época da seca, e os indígenas deslocam-se para lugares piscosos, levando consigo todos os seus apetrechos caseiros, crianças e cachorros, para pescarem de maneiras diversas. De varas e folhas de palmeiras rapidamente são construídas barracas, e a vida ferve nas grandes praias que ficaram desnudadas, quando as águas se retiraram. As mulheres preparam logo uma parte dos peixes para as refeições, mas a maior parte dos peixes será conservada, secando-a nos moquéns, que são grelhas grandes de varas verdes elevadas sobre um fogo lento. O peixe seco, defumado servirá de alimento nos dias de chuva, que não faltam nem na época da seca. Tendo esgotado o peixe num lugar, todo o bando muda-se para outro lugar. Os indígenas na média, permanecem três meses, nessa peregrinação." (2005 [1909]: p. 393, sic)
\end{abstract}

Nos trabalhos etnográficos há, ainda, informações sobre a domesticação de animais tanto para fins de alimentação, como para garantir, por exemplo, as plumas necessárias à aerodinâmica de flechas e dos artefatos confeccionados para o cotidiano e eventos rituais. Os trabalhos referem, também, a presença de xerimbabos (animais de estimação) de forma frequente em quase todas as aldeias. Entre os Xikrín do Cateté, por exemplo, há alguns anos atrás, era possível encontrar aves sem penas, colocando nova plumagem, pois a emplumação anterior foi utilizada, pela mulheres, para preparar diversos artefatos. As aves eram "apanhadas" para serem criadas e cuidadas como xerimbabo e fonte de matéria prima.

Quando os itens das monografias clássicas descrevem a cultura material dos povos indígenas, é possível se aperceber da técnica e do cuidado de especialistas

\footnotetext{
"[a]pesar de totalmente alheios à experiência embarcada, durante a infância os filhos de pescadores costeiros vivem intensamente a relação com o barco e com a água, exercitando antecipadamente o tipo de relações em que estarão envolvidos no futuro." (2013: p. 513) E Silva chama atenção para escolha dos lugares entre os Arukwayene, como informa a autora: "[p]ara além do caráter utilitário das ivaynti, sobre as quais, no período de seca, todo o transporte de pessoas e mercadorias é realizado, as pontes se tornaram também espaços de convivência, brincadeiras, encontros e esperas." (2016: p. 568)
} 
no fabrico de utensílios domésticos; instrumentos de caça, pesca e coleta; e adereços rituais e cotidianos.

As atividades de subsistência são amparadas pela organização social do coletivo indígena que traça estratégias de aliança para manter as relações sociais e de parentesco em ordem. Entre os Tapirapé, as famílias - à época do trabalho realizado por Herbert Baldus (1970) - eram extensas, chefiadas por um homem, mais experiente e de certo prestígio social, que reunia jovens para seu grupo familiar, por meio de residência matrilocal. ${ }^{5} \mathrm{E}$ os maridos das jovens passavam a cooperar com o líder, quando este empreendia caçadas ou colocava roças. As relações de trabalho são "costuradas", a partir do parentesco, pois implicam em reciprocidade e obrigações entre parentes consanguíneos e afins. Hoje, muito se modificou, em face das relações sociais permanentes entre povos indígenas e com as sociedades não indígenas, como veremos a seguir.

\section{Notas sobre imposições}

Urge pensar que a realização de trabalho entre povos indígenas se faz em função da cultura e dos contextos históricos, razão pela qual se insiste na contextualização das atividades laborais.

É importante compreender que, desde a chegada dos europeus ao Brasil, o processo de trabalho, entre os povos indígenas, é organizado sob valores que podem estar integrados a diversos domínios quer eles sejam, unicamente, sociais (strictu senso) ou religiosos, o que aumenta a complexidade das relações estabelecidas.

As complexas relações concebidas entre os coletivos indígenas não impediu - tampouco impede, hoje - as investidas do colonizador estrangeiro e/ou interno que forja novas relações de trabalho, influenciada pelo processo de monetarização que produz a diminuição dos territórios indígenas, com a prática de sedentarização, como disse certa vez Hõpryre Rõnôre Jõpikti (Paiaré), líder Akrã- Kyikatêjê, "os brancos fizeram os chiqueiros [territórios demarcados] e querem que os índios

\footnotetext{
${ }^{5} \mathrm{O}$ sistema matrilocal, exige que os homens, ao casarem, se desloquem para aldeia de suas mulheres. A mudança implica em complexas relações sociais e de parentesco que procura manter 0 equilíbrio dos coletivos indígenas.
} 
fiquem dentro. Antes era só liberdade." ${ }^{\circ E l e ~ s e ~ r e f e r i a, ~ e m ~ f o r m a ~ d e ~ l a m e n t o, ~ a ~ c o m o ~}$ as restrições do território original tolhia a liberdade de se movimentar conforme as necessidades de subsistência e os padrões tradicionais de relacionamento. Comparava a terra demarcada a chiqueiros, porque nem sempre se ouvia os indígenas e se respeitava a relação destes com a terra.

Os contextos históricos a partir dos quais se pode entender o trabalho entre povos indígenas são muitos, entretanto para demonstrar os efeitos sociais das imposições feitas aos povos indígenas, aqui se selecionou o período ditatorial estabelecido no Brasil, nos anos sessenta do século passado, que será lido via Relatório Figueiredo, documento elaborado pelo próprio Estado brasileiro, que expõe as mazelas da política indigenista adotada na primeira metade do século XX.

Procurar-se-á demostrar, como os povos indígenas sofreram com as imposições do Serviço de Proteção aos Índios (SPI) encarregado da política indigenista, no Brasil.

\section{Do Relatório Figueiredo}

Durante quase meio século as atrocidades ocorridas em tempos ditatoriais ficaram "desaparecidas" entre as linhas do Relatório Figueiredo (RF) "abandonado", em meio a muitos outros documentos no Museu do Índio, no Rio de Janeiro. Os/as estudiosos/as sabiam da existência do documento, entretanto não conheciam o teor das investigações levadas a efeito, pela Comissão de Inquérito, presidida pelo procurador Jader de Figueiredo Correia, porque supostamente o documento teria ardido em incêndio ocorrido no Ministério da Agricultura.

O conjunto documental, constituído por 30 volumes, com mais de sete mil folhas, faz do Relatório Figueiredo, talvez, o mais importante registro que permite pensar a relação do Estado brasileiro com os povos indígenas, especialmente se a etnicidade for tomada como política, que permite ver o genocídio inscrito nas amareladas folhas do processo, indicando a opção do Estado brasileiro.

Em 2012, o RF foi encontrado pelo pesquisador Marcelo Zelic, vicepresidente do grupo Tortura Nunca Mais de São Paulo, que colocou ao alcance de estudiosos/as a partir do Armazém da Memória.

${ }^{6}$ Em conversa sobre as relações indígenas e não indígenas na Reserva Indígena Mãe Maria, em 1998. 
O documento revela as faces do indigenismo ou da política indigenista, no Brasil, e altera radicalmente a visão da História Indígena que, se antes da "descoberta" do RF, restava-nos a suspeita dos crimes cometidos contra os povos indígenas; hoje, não faltam argumentos para indicar a crueldade das ocorrências, as quais abalam pessoas indígenas de diversas etnias, apenas pela leitura de trechos do referido documento.

Aqui, nos detemos nas relações de trabalho impostas às pessoas e coletivos indígenas, que indicam os atentados à tradição de subsistência, mantida pelos povos indígenas, os quais comprometeram sua sobrevivência, especialmente quando, deslocados forçosamente, sucumbiram ou amargaram a distância do território original em função da prática estatal.

\section{Casos emblemáticos}

Diz o procurador, no Relatório Síntese (RS), ao encaminhá-lo ao Ministro do Interior, que: "palmilhando o campo em todos os sentidos o índio fixou-se nos sítios onde o solo mais rico permitia maior abundância de elementos para sua atividade típica de colheita." (RF - Síntese: fls. 4919).

Nas folhas do Relatório Figueiredo quando o rol de crimes cometidos pelos funcionários do SPI, considerados pelo procurador Jader de Figueiredo, como "... verdadeiros celerados, que thes impuseram um regime de escravidão [aos/as indígenas] e thes negaram um mínimo de vida compatível com a dignidade da pessoa humana." (RF - Síntese: fls. 4912) O que o permite afirmar que, mesmo não tendo a veleidade de conhecer o Serviço de Proteção aos Índios (SPI), "o pouco que Ihe foi dado a ver é suficiente para causar espanto e horror." (RF - Síntese: fls. 4911)

E, a observação acurada Ihe permitiu verificar que no Posto Indígena (PI) Cacique Doble, a "produção agrícola seria suficiente para dar-Ihes maior conforto do que os seus bem assistidos vizinhos do PI Paulino de Almeida." (RF - Síntese: fls. 4918, sic)

Constatou, o zeloso procurador, que "o patrimônio indígena é fabuloso. As suas rendas alcançam milhões de cruzeiros novos se bem administrados. Não requereria um centavo sequer de ajuda governamental e o índio viveria rico e saudável nos seus vastos domínios." (RF - Síntese: fls. 4919) 
É necessário considerar que, no SPI, dominava a "mentalidade empresarial", como informa Cardoso de Oliveira, a partir do momento em que os diretores do órgão "... passaram a ser recrutados entre homens completamente divorciados da doutrina de Rondon, fossem eles civis ou militares."(1972 [1968]: p. 74) A referida mentalidade tentava transformar os postos indígenas - unidades bases do SPI implantadas em diversas aldeias indígenas, em empresas dedicadas a produção e lucro que integrariam a chamada Renda Indígena. Como diz Cardoso de Oliveira,

"a concepção inerente a essa orientação é a de que o índio só pode 'civilizar-se' pelo trabalho induzido, o que lhe é ensinado pelo civilizado. E a consequência imediata disso é tornar o Posto Indígena uma unidade auto-suficiente, o que viria dispensar verbas orçamentárias destinadas à assistência e à proteção. ."(1972 [1968]: p. $74-75$, sic)

Não parece à toa o SPI, chamou-se no momento de sua criação, em 1910, de Serviço de Proteção aos Índios e Localização de Trabalhadores Nacionais (SPILTN), o interesse da recém criada República era adaptar-se aos padrões internacionais de exploração de mão-de-obra e produção capitalista, obrigando os povos indígenas a abandonar as relações sociais baseadas em reciprocidade e na não produção de excedentes.

O procurador, como excelente funcionário do Estado brasileiro, comungado da ideia de imposição do trabalho, feita aos indígenas, declara:

"[p]roclama-se à míngua de recursos orçamentários escondendo-se que o índio brasileiro, um dos maiores latifundiários do mundo, tem meios de auferir rendas de suas terras, de suas dezenas de fazendas, capazes de tornar cada um deles imensamente rico se convenientemente administrados, com zelo e honestidade. São milhões de hectares de terras espalhados em quase todo o País, justamente nas regiões mais férteis, nos lugares mais aprazíveis, nos climas mais amenos." (RF - Síntese: fls. 4919, sic)

Para ler o Relatório Figueiredo, na chave "trabalho indígena" é preciso escoimar, em meio as informações sobre fome e desnutrição sofridas pelos povos indígenas para, então, identificar as relações econômicas que impõem os escorchantes padrões capitalistas aos "donos da terra." 
São emblemáticos os casos de esbulho da terra produzindo o deslocamento forçado de povos indígenas. Na sequência, as terras "livres" de seus moradores, ou mesmo "com" seus moradores, eram arrendadas aos empresários da região.

"Os Kadiweus (antigos Guaicurús), donos de ricas terras que Ihes deu o Senhor D. Pedro II pela decisiva ajuda à tropas brasileiras naquela região durante a Guerra do Paraguai, sentem-se escorraçados em seus domínios, o seu gado vendido e suas mulheres prostituídas." (RF - Síntese: fls. 4919, sic)

Imagine-se a arbitrariedade, os Kadiweu receberam seus próprios domínios como doação, no Império, pela suposta magnitude de D. Pedro II, e alguns anos depois, foram despojados de suas terras. $O$ gado que conseguiram criar foi vendido por terceiros e suas mulheres obrigadas a trabalhar como profissionais do sexo. A diferença em relação aos não indígenas, no caso da prostituição, é que as kadiweu era exploradas pelos cafetões do SPI.

Para Jader de Figueiredo, o modelo de administração exemplar do SPI, era o Posto Indígena Paulino de Almeida, no Rio Grande do Sul, pois "àquele Pôsto, o único dêsse nome de que a $\mathrm{Cl}$ [Comissão de Inquérito] têm notícia, administrado em elevados padrões de decência, tem hoje excelente produção agrícola e seus índios gozam de apreciável "status" sócio-econômico-cultural." (RF - Síntese: fls. 4920, sic)

Fica ao leitor a possibilidade de imaginar o grau de coerção praticada para obrigar os indígenas a produzir nos moldes "de empresa" desejados pela política indigenista. Muitas vezes, além do arredamento das terras, nos domínios indígenas eram instaladas serrarias para promover a derrubada de madeira de lei (mogno, cedro, castanheiras entre tantos outros), a qual poderia ser vendida como matéria prima ou, ainda, minimamente beneficiada em tábuas.

Entre os muitos exemplos de extração ilegal de madeira, temos a denúncia contra Alan Kardec Martins Pedrosa que diz ser ele o

"responsável pela venda irregular de 500 pinheiros no Pôsto Indígena Xavier da Silva, em Londrina, com edital publicado na Folha de Londrina, quando a coleta foi feita em Curitiba, dando ganho de causa à Serraria Santa Tereza, de Kantor \& Franco Ltda. com preço de $\operatorname{Cr} \$ 19.000$, simplesmente porque pagava à vista quando a Serraria Irerê, de Isidro Maximino, ofertou Cr\$21.050 dentro das 
cláusulas do edital - Prejuízo para repor Cr\$1.025,00." (RF -

Síntese: fls. 4927, sic)

Observe-se que Cardoso de Oliveira (1972[1968]) indicou a mentalidade empresarial e esta preside a observação constante do $\mathrm{RF}$, o procurador não condena o arrendamento e a devastação das terras, mas sim a perda de lucros pela forma da transação.

Nos registros constantes do RF, está explícito o uso de mão-de-obra indígena, como no município de Tenente Portela, quando Acir Barros permitiu que seus correligionários políticos e autoridades “... lavrassem gratuitamente as terras indígenas ... com o agravante da utilização do braço indígena. "(RF - Síntese: fls. 4926) Muitos funcionários do SPI eram coniventes com a assinatura de contratos irregulares de arrendamento de terras indígenas, denunciados que são nas folhas do RF.

O procurador diz a certa altura do RF que para comprovar as fraudes e 0 incentivo as mesmas,

"basta citar a atitude do Diretor Major Aviador Luis Vinhas Neves, autorizando todas as Inspetorias e Ajudâncias a vender madeira e gado, e arrendar terras, tudo em uma série de Ordens de Serviço Internas cuja sequência dá uma triste ideia daquela administração. (Fls. 4065 a 4088). (RF - Síntese: fls. 4920)

E, Jader de Figueiredo prossegue as acusações: "[a]liás esse militar pode ser apontado como padrão de péssimo administrador, difícil de ser imitado, mesmo pelos seus piores auxiliares e protegidos. "(RF - Síntese: fls. 4920)

Em outros momentos, as terras devastadas recebiam pasto e a pata de bovinos e ocupava a extensão das terras indígenas, muitas vezes, a partir da compra de reprodutores pelos chefes de posto, em benefício próprio, transformando as pessoas indígenas em vaqueiros não remunerados, vivendo em péssimas condições de pastoreio. E segundo o RF,

“... não para ainda a espoliação do índio. Aquilo que não podia render dinheiro farto e fácil podia ser distribuído ou tomado pelos poderosos locais, por seus afilhados ou testas de ferros. Os dirigentes do SPI nas diziam ou providenciavam para obstaculizar [desmandos e irregularidades]." (RF - Síntese: Fls. 4925) 
Cultivar o solo era atividade mais frequente nas terras indígenas, pois sedentarizados, os/as indígenas colocavam roças, entretanto essas atividades não observavam os preceitos tradicionais de cada etnia. Eram extensas roças de uma só cultura: milho, arroz ou trigo entre outros gêneros de grande aceitação no comércio local. Os indígenas preparavam a terra, semeavam e colhiam os frutos entretanto, em muitos postos, aos indígenas restava alimentar-se com "grãos de milho seco e mamão verde cortado em pedaços." e mesmo assim os precários alimentos, que não faziam parte da dieta alimentar dos/as indígenas, eram distribuídos ao talante do administrador, pois tudo que era produzido pelos/as indígenas, inclusive grandes quantidades de farinha de mandioca, que era vendida e os produtores indígenas não auferiam renda alguma, os valores eram embolsados pelo administrador. (RF Vol. VIII: fls. 1681).

O trabalho escravo - como conceituado pelo autor do RF - era a regra nos domínios do SPI. A noção de trabalho escravo, no RF, está associada a não remuneração e a péssimas condições de trabalho que gerava vidas precarizadas pela operação de poder desfechada pelo Estado que insta a chamada feita por Judith Butler de condição precária que, no caso estudado, aponta os povos indígenas como "enlaçados" em "redes sociais e econômicas de apoio deficientes, ..." expondo-os de diversas formas "... às violações, à violência e à morte. (BUTLER, 2015: p. 45)

Uma vez que o Estado vive um embate eterno com os povos indígenas, impondo aos mesmos uma guerra sem fim, pois a cada imposição de paz, os direitos são esquecidos e a luta dos movimentos indígenas continua, atravessando os séculos. (SOUZA LIMA, 1995)

Em diversos registros é possível vislumbrar os números da produção agrícola, pois apenas no Relatório síntese há inúmeros registros. Por exemplo, "Luiz Martins Cunha, vendia grandes partidas de gêneros da produção do Posto para manutenção de sua família em regime de mesa lauta" (RF - Síntese: fls. 4918). Ou como em Cacique Doble que a produção agrícola era satisfatória para bem prover os moradores do lugar. No Posto Indígena Santana informa-se que sem a devida concorrência pública, foram vendidos 75 sacos de arroz, por Alberico Soares Pereira. (RF - Síntese: fls. 4927). Attilio Mazzaloti cultivou e arredou ilegalmente terras indígenas em benefício próprio. (RF - Síntese: fls. 4929) 
que mais causa espécie nos registros do Relatório Figueiredo diz respeito as discriminações de gênero contra indígenas mulheres obrigadas ao trabalho. Inúmeros funcionários são acusados de coloca-las para trabalhar em situações absolutamente desumanas. Flávio de Abreu é acusado de mandar “... as parturientes para os roçados um dia após o parto, deixando as criancinhas em uma mansarda imunda sem terem direito de alimentar os próprios filhos." (RF - Síntese: fls. 4937).

O mesmo administrador, "suspendia as aulas e mandava as crianças para o eito, porque os adultos estavam de castigo, trabalhando noutras fazendas." (RF Síntese: fls. 4937), Pelo exposto, é possível dizer que, não apenas, os homens adultos eram "escravizados", as indígenas mulheres e as crianças eram obrigadas a trabalhar de sol a sol, sem direito a condições de trabalho decente. E, nas entrelinhas do RF, sabe-se que a quaisquer ameaças de reação dos povos indígenas contra a conduta dos/as funcionários/as, os/as membros do coletivo eram desterrados/as, a título de castigo, para outros espaços, evitando assim que o regime de trabalho implantado pudesse ser revertido. Muitas vezes, a não obediência cega aos funcionários gerava sessões de suplício (tortura) e prisões arbitrárias. Evidentemente, dada a não adaptação dos/as indígenas ao regime de escravização, as punições eram diárias.

Entre os suplícios (torturas) mais comuns descrito no RF temos o "tronco", assim descrito:

“... o mais encontradiço de todos os castigos, imperando na $7^{\mathrm{a}}$. Inspetoria. Consistia na trituração do tornozelo da vítima, colocandoo entre duas estacas enterradas juntas em ângulo agudo. As extremidades, ligadas por roldanas, eram aproximadas lenta e continuamente." (RF - Síntese: fls. 4913).

O volume VII do Relatório Figueiredo traz inúmeras imagens das situações encontradas pela Comissão de Inquérito, presidida por Jader de Figueiredo. As fotografias, em uma rápida passada de olhos, parecem pousadas para confirmar o trabalho nos postos, pois são demonstração de resultados da colheita de milho, de trigo quando, muito provavelmente, os/as indígenas eram fotografados para comprovar a tese de que, submetidos a um regime disciplinar, os/as indígenas poderiam civilizar-se, via trabalho, criando excedentes agrícolas para venda, mesmo em completo desacordo com os valores de sua cultura. 
As situações de trabalho não cessam com as denúncias acima. No volume VIII do RF há referências aos contratos de extração de minérios indicando haver

\begin{abstract}
"exploração de cassiterita, em Rondônia, na região do Igarapé Floresta dos índios ariquemis; que são conhecidos como principais compradores uma francesa denominada Jaqueline, Plínio Benfica, Flodoaldo Fontes Pinto e um tal Jucá; que o contrato de exploração de minérios firmados por Maj. Neves parece ter sido denunciado pelo Ministro da Agricultura Sr. Ney Braga; que o comenta-se no SPI que o inspetor Alberico Soares arestado [arrestado] da chefia da IR9, em virtude de haver denunciado exploração de índios no trabalho de cassiterita, vinte e quatro horas depois do fato; que a comentada matança dos índios Cinta Largas se prende ao caso da cassiterita em Roraima; ..." (RF, vol. VIII: fls. 1579-1580, sic)
\end{abstract}

Talvez, o trabalho na mineração de cassiterita é, provavelmente, o mais distante da tradição de trabalho entre indígenas, e produz uma corrida de garimpeiros à área fato que traz efeitos sociais indeléveis para os indígenas e moradores/as do entorno da mina.

Acredita-se que o garimpo de cassiterita - informado no RF - coincide com o hoje, chamado garimpo do Bom Futuro, localizado no município de Ariquemes, em Rondônia, considerada como a maior jazida de cassiterita do mundo. Da descoberta da jazida aos dias atuais, calcula-se que cerca de 30 mil garimpeiros passaram pela região. Pelos números referidos, imagina-se o que o fato significou e, ainda, significa, para os povos indígenas da região: conflitos de interesse intermináveis.

\title{
De volta ao início
}

Para responder as perguntas propostas à partida, apontam-se algumas veredas que respondem parcialmente os desafios. O que é ser trabalhador/a entre os povos indígenas? Para responder a interrogação temos que considerar, sobretudo, as relações permanentes entre sociedades indígenas e destas com a sociedade nacional, especialmente, porque o contato modifica as relações sociais tradicionais, e de alguma forma aponta novos horizontes de trabalho. É importante considerar que os povos indígenas, como portadores de etnocidadania ou dupla cidadania, são ao mesmo tempo indígenas e cidadãos/ãs brasileiros/as, com os direitos devidamente assegurados pela Constituição de 1988. (Luciano, 2006; Beckhausen, 2008) 
E ao responder o que é o disciplinamento imposto pelo trabalho aos/as indígenas? Considera-se que o disciplinamento espúrio, vindo dos tempos coloniais, compromete os coletivos indígenas, trata-se da imposição do regime de trabalho mercantil, em tempos coloniais, ainda pelos portugueses e demais estrangeiros que por aqui aportaram. Mas, após a constituição do Estado nacional, o regime capitalista, continuou produzindo o genocídio, iniciado pelos europeus, que dizimou aos milhares membros de coletivos indígenas e, mesmo, e povos indígenas Brasil afora foram extintos. ${ }^{7}$

Que fazem os povos indígenas como trabalho? Pescam, praticam a coleta, caçam, põem roça, quando estão em seus territórios? Em seus territórios, garantidos ou não pela demarcação, os povos indígenas praticam suas atividades de tradicionais com as modificações impostas ou adquiridas em face das alterações produzidas pela proximidade com os não indígenas. Evidentemente, as mudanças não se fazem sentir de pronto, vão sendo incorporadas cotidianamente de acordo com a dinâmica cultural e a agência indígena.

Com o tempo e a luta intermitente dos movimentos indígenas, fortalecidos muito especialmente a partir dos anos setenta do século passado, reivindicando territórios, educação e saúde. A rota dos povos indígenas foi mudando e eles foram se inserindo em muitas atividades, hoje, trabalham em suas aldeias, como professores, agentes de saúde, agentes de saneamento. Fato que em muito auxilia o fazer política indígena. Entretanto, o assalariamento precisa ser estudado com parcimônia.

E quando estão nas cidades, após deslocamentos forçados ou não, o que fazem como trabalho? Um pouco de tudo na medida em que encontram formação universitária, nos dias de hoje muitos sãos os/as intelectuais indígenas que se encontram nas cidades trabalhando como advogados/as, professores/as, educadores/as, antropólogos/as, entre outras tantas possibilidades.

As mudanças nas relações de trabalho aconteceram, entretanto a intolerância e a violação dos direitos de povos etnicamente diferenciados continuam a ocorrer e, elas embaçam a possibilidade de relação menos conflituosa.

7 Sobre o assunto, e para aprofundar a discussão, considero importante ler o Relatório Figueiredo/Síntese; o Relatório da Comissão Nacional da Verdade no que diz respeito aos Povos Indígenas; e ainda, o recém saído Relatório do CIMI com os dados de 2017 sobre: Violência contra os povos indígenas no Brasil. Documentos e publicações que dão ao leitor a real dimensão do genocídio que ainda acontece e que sempre foi negado. 


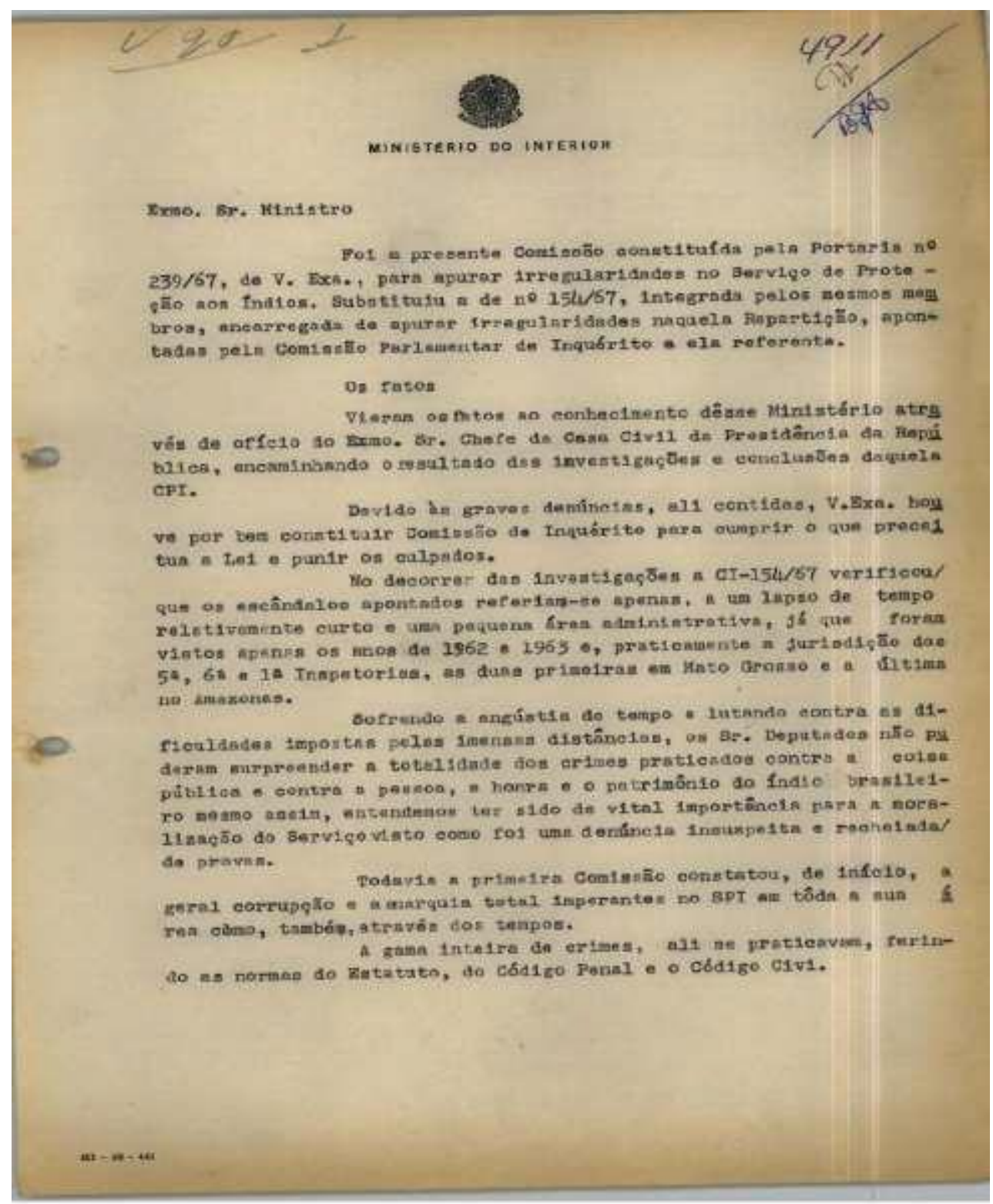

Fonte: Relatório Figueiredo, folha 4911

http://pt.scribd.com/doc/142787746/Relatorio-Figueiredo

\section{Referências}

\section{Documental}

BRASIL. Relatório Figueiredo: documento na íntegra. Disponível em: http://racismoambiental.net.br/2013/06/02/relatorio-figueiredo-documento-naintegra7-mil-paginas-pdf-pode-agora-ser-baixado/. 2013. Acesso em 01 de julho de 2017. 
BRASIL. Comissão Nacional da Verdade (CNV). 2012. "Povos Indígenas e Ditadura Militar - Subsídios à Comissão Nacional da Verdade 1946-1988"In: Relatório parcial 01 de 30/11/2012. Disponível em: https://idejust.files.wordpress.com/2012/12/povosindc3adgenas-e-ditadura-militar-relatc3b3rio-parcial-30 11 2012.pdf.

CIMI. 2018. Relatório Violência contra os Povos Indígenas do Brasil - Dados de 2017. Brasília.

Depoimento de Hõpryre Rõnôre Jõpikti (Paiaré), líder Akrã- Kyikatêjê, em set.1998. (Arquivo J. F. Beltrão)

\section{Bibliográficas}

BALDUS, Herbert. Tapirapé - Tribo Tupí no Brasil Central. São Paulo: Cia Editora Nacional/EdUSP, 1970.

BECKHAUSEN, Marcelo Veiga. "Etnocidadania, direitos originários e a inconstitucionalidade do poder tutelar" In: PIOVESAN, Flávia; IKAWA, Daniela; SARMENTO, Daniel (Orgs.). Etnocidadania, direitos originários e a inconstitucionalidade do poder tutelar. Lumen Juris, 2008, v. , p. 82-102.

BUTLER, Judith. Quadros de Guerra, quando a vida é passível de luto? Rio de Janeiro: Civilização Brasileira, 2015 [2009].

CARDOSO DE OLIVEIRA, Roberto. "O índio na consciência nacional (1965)" In A Sociologia do brasil Indígena. São Paulo: Tempo brasileiro/EdUSP, 1972 [1968].

KOCK-GRÜNBERG, Theodor. Dois anos entre os Indígenas - viagens no noroeste do Brasil (1903/1905). Manaus: EDUA, 2015 [1909].

LUCIANO, Gersem José dos Santos. O Índio Brasileiro: O que você precisa saber sobre os povos indígenas no Brasil de Hoje. Brasília: MEC/SECAD MUSEU NACIONAL/UFRJ, $2006 . \quad$ v. $1.232 p$. Disponível em: http://unesdoc.unesco.org/images/0015/001545/154565por.pdf.

NIMUENDAJÚ, Curt. "Os Apinayé" In Boletim do Museu Paraense Emilio Goeldi. Belém: MPEG, 1956.

SAUTCHUK, Carlos Emanuel. "Pesca e aprendizagem: Gestação e metamorphoses no estuário do Amazonas" In: Amazônica - Revista de Antropologia. (Online) vol. 5, no. 2: p. 502-519, 2013.

SILVA, Elissandra Barros da. "Sobre aquela ponte existe um mundo: Ivaynti e os Arukwayene no Urucauá" In: Amazônica - Revista de Antropologia. (Online) vol. 8, $n^{\circ}$. 2: p. 568-608, 2016.

Recebido em: 16 de agosto de 2018. Aprovado em: 29 de setembro de 2018. Publicado em: 22 de novembro de 2018. 